\title{
Reparasi Perahu Fiberglass bagi Nelayan Kabupaten Takalar
}

\author{
Zulkifli A. Yusuf ${ }^{1 *}$, M. Rusydi Alwi ${ }^{1}$, Ganding Sitepu ${ }^{1}$, Andi Haris Muhammad ${ }^{1}$, Baharuddin ${ }^{1}$, \\ Andi Husni Sitepu ${ }^{1}$, M. Iqbal Nikmatullah ${ }^{1}$, Lukman Bochary ${ }^{2}$, Misliah $^{2}$ \\ Departemen Teknik Sistem Perkapalan, Fakultas Teknik Universitas Hasanuddin ${ }^{1}$ \\ Departemen Teknik Perkapalan, Fakultas Teknik Universitas Hasanuddin ${ }^{2}$ \\ Navalarchitecture@gmail.com*
}

\begin{abstract}
Abstrak
Kelompok Nelayan "Karya Bersama” merupakan salah satu kelompok nelayan di Desa Galesong Kota Kecamatan Galesong Kabupaten Takalar yang menggunakan perahu fiberglass dalam kegiatan penangkapan ikan. Perahu fiberglass yang digunakan sangat membantu nelayan dalam meningkatkan hasil tangkapannya. Berdasarkan observasi awal ditemukan beberapa perahu fiberglass milik mitra yang mengalami beberapa kerusakan. Kerusakan perahu fiberglass yang mereka pakai tidak bisa dihindari akibat kondisi perairan lokasi penangkapan ikan yang tidak bersih dan besarnya ombak. Perbaikan perahu fiberglass secara tepat tidak bisa mereka lakukan secara mandiri karena pengetahuan dan keterampilan teknik reparasi perahu fiberglass yang mereka miliki masih rendah. Kegiatan pengabdian ini bertujuan untuk meningkatkan pengetahuan dan keterampilan mitra dalam teknik reparasi perahu fiberglass. Kegiatan dilakukan dengan dua tahap yaitu 1) Penyuluhan tentang teknologi bahan fiberglass, jenis-jenis kerusakan pada perahu fiberglass dan teknik perbaikannya. 2) Pelatihan reparasi perahu fiberglass. Evaluasi peningkatan pengetahuan peserta dilakukan dengan pre-test dan post-test setelah dilakukan penyuluhan. Evaluasi ketrampilan peserta dilakukan pada saat pelatihan langsung. Hasil kegiatan menunjukkan bahwa $90 \%$ dari 10 orang peserta yang mengikuti pelatihan telah memiliki pengetahuan yang baik tentang bahan fiberglass dan teknik reparasi perahu fiberglass dan mampu melakukan perbaikan kerusakan perahu fiberglass secara benar.
\end{abstract}

Kata Kunci: Nelayan; Reparasi; Perahu; Fiberglass; Desa Galesong Kota.

\begin{abstract}
The "Karya Bersama" Fishermen Group is one of the fishermen groups in Galesong Kota Village, Galesong District, and Takalar Regency who uses fiberglass boats for fishing activities. The fiberglass boats used are very helpful for fishermen in increasing their catch. Based on field observations, it was found that several fiberglass boats belonging to partners were damaged. The damage to the fiberglass boats they use cannot be avoided due to the unclean waters of the fishing location and the large waves. They cannot do proper fiberglass boat repair independently because their knowledge and skills in fiberglass boat repair techniques are still low. This service activity aims to improve partners' knowledge and skills in fiberglass boat repair techniques. The activity was carried out in two stages, namely 1) Counseling about fiberglass material technology, types of damage to fiberglass boats and repair techniques. 2) Fiberglass boat repair training. Evaluation of the increase in participants' knowledge was carried out by means of a pre-test and post-test after counseling. Evaluation of participants' skills is carried out during hands-on training. The results of the activity showed that $90 \%$ of the 10 participants who took part in the training had good knowledge of fiberglass materials and fiberglass boat repair techniques and were able to properly repair damaged fiberglass boats.
\end{abstract}

Keywords: Fishermen; Repair; Boat; Fiberglass; Galesong Kota Village.

\section{Pendahuluan}

Kabupaten Takalar terletak antara $5,3^{0}-5,33^{0}$ Lintang Selatan dan antara $119,22^{0}-118,39^{0}$ Bujur Timur memiliki luas wilayah sekitar $566,51 \mathrm{~km}^{2}$, dimana $240,88 \mathrm{~km}^{2}$ diantaranya merupakan wilayah pesisir dengan panjang garis pantai sekitar $74 \mathrm{~km}$ dan luas pantai sekitar 246,99 $\mathrm{km}^{2}$ yang berpotensi terhadap sektor perikanan tangkap (Bappeda Kab. Takalar, 2018). Kecamatan 
Galesong Kab. Takalar merupakan salah satu wilayah yang berkontribusi terhadap PDRB Kabupaten Takalar dari sektor perikanan dimana di tahun 2016 menghasilkan 945 ton perikanan laut (BPS Kab.Takalar, 2018). Desa Galesong Kota Kec. Galesong Kab. Takalar memiliki 80\% penduduknya bekerja sebagai nelayan tangkap diantaranya kelompok nelayan "Karya Bersama" sebagai mitra dalam kegiatan ini. Hasil wawancara dengan mitra mengungkapkan bahwa sejak menggunakan perahu fiberglass, pendapatan mereka telah meningkat. Akan tetapi jika perahunya mengalami kerusakan dapat menyebabkan mereka tidak bisa melaut. Mitra tidak bisa menghindari kerusakan pada perahu fiberglassnya disebabkan karena kondisi perairan lokasi penangkapan ikan yang tidak bersih dan besarnya ombak. Lambung perahu sering mengalami keretakan akibat hantaman balok kayu yang hanyut diperairan. Mitra mengungkapkan bahwa kondisi perahu yang rusak berat tidak bisa mereka perbaiki dikarenakan biaya reparasi perahu oleh bengkel produksi fiberglass yang mahal dan tidak terjangkau bagi mereka. Mitra hanya bisa melakukan perbaikan sekedarnya sehingga tidak mengatasi kerusakan yang terjadi secara maksimal.

Permasalahan utama yang dihadapi mitra adalah mereka tidak bisa melakukan perbaikan secara tepat dan mandiri karena masih rendahnya pengetahuan dan keterampilan terhadap teknik reparasi perahu fiberglass. Permasalahan yang dihadapi oleh mitra tersebut mengakibatkan mereka tidak optimal dalam operasional penangkapan ikan yang berdampak pada berkurangnya produksi hasil tangkapan ikan. Permasalahan tersebut diatas bagi mitra dianggap sangat perlu untuk ditangani karena berdampak langsung pada pendapatan mereka dalam menghidupi keluarga dan keberlangsungan pekerjaan mitra sebagai nelayan tangkap.

Kegiatan PPM ini berupa transfer ipteks dengan memberikan input teknologi perahu fiberglass berupa kegiatan penyuluhan dan pelatihan teknik reparasi perahu fiberglass. Target yang ingin dicapai melalui pelatihan ini adalah meningkatnya pengetahuan dan keterampilan mitra tentang teknik reparasi perahu fiberglass.

Pelatihan dan pendampingan adalah metode yang banyak digunakan saat ini untuk meningkatkan kemampuan dan keterampilan masyarakat. Efektifitas pelatihan dan pendampingan perbaikan perahu fiberglass dapat meningkatkan keterampilan kerja peserta sehingga dapat menjamin ketersediaan perahu yang akan menjaga proses produksi tetap berjalan lancar (Wahyuddin, 2018).

\section{Latar Belakang Teori}

Fiberglass Reinforced Plastics (FRP) atau yang biasa disebut dengan fiberglass adalah produk yang terdiri dari resin, bahan penguat fiberglass (roving mat) dan bahan tambahan katalis yang digabung dan diproses agar didapat kinerja yang spesifik sesuai kebutuhan. Perahu fiberglass efektif untuk meningkatkan produktivitas hasil tangkapan nelayan dan menekan pengeluaran biaya penangkapan ikan. Umur pakainya lebih lama, kekuatannya tinggi, tahan korosi, ringan, biaya produksi serta perawatan jauh lebih murah dibanding kapal kayu, tidak memerlukan pengecatan yang berulang-ulang.

Kerusakan perahu fiberglass dapat terjadi sejak tahap pembuatan atau dalam tahap pemakaian. Sebagian besar pekerjaan perbaikan yang ditemukan pada perahu fiberglass adalah perbaikan ringan seperti keretakan. Sebagian besar retakan yang muncul bertahap dan menjadi lebih buruk dari waktu ke waktu, dan yang paling sering ditemukan di daerah laminasi padat. Semakin lama 
laminasi dibiarkan untuk flex, maka dampaknya akan lebih besar, yaitu semakin dalam retak. Celah yang lebih dalam meluas ke laminasi, kekuatan panel berkurang.

Kerusakan pada perahu mitra terjadi saat pemakaian berupa keretakan akibat benturan dan lubang kena benda tajam. Kerusakan akibat kebocoran badan perahu adalah jenis kerusakan perahu fiberglass yang sering ditemui akibat tabrakan dengan perahu lain atau benda asing dilaut. Struktur lambung sangat rentan mengalami kerusakan atau patah atau retak saat pemakaian normal, akibat mengalami benturan dengan objek lain, kandas dan atau karena penggunaan bahan tidak sesuai dengan standar (System, 2014).

Sebuah lubang jarum dalam sebuah perahu fiberglass adalah sebuah lubang kecil yang dapat menyebabkan masalah besar. Jika lambung tidak kedap udara, air akan meresap dan merusak perahu dari dalam melalui cetakan dan membusuk. Biasanya kebocoran akan diketahui minimal dengan inspeksi visual dari kerusakaan yang dicurigai. Jika tidak bisa di inspeksi dengan visual, maka dilakukan teknik tapping yakni menandai daerah yang dicurigai terjadi kerusakan. Jika sudah konfirm maka langkah selanjutnya adalah membuat lubang kecil untuk dilakukan perbaikan.

Langkah perbaikan kebocoran yang dilakukan adalah:

1) Setelah mengetahui jenis kerusakan, beri tanda pada titik lokasi kerusakan.

2) Bersihkan titik yang rusak hingga serat fiber yang lama kelihatan dengan menggunakan amplas maupun gerinda tangan. Permukaan yang tidak bersih dapat menyebabkan tambalan baru akan mengelupas.

3) Sebelum melakukan penambalan, dilakukan dulu pemotongan serat fiber sesuai luas yang dibersihkan.

4) Selanjutnya oleskan gel (campuran resin dan katalis) pada tempat yang sudah dibersihkan secara merata, lalu tempelkan potongan serat fiber kemudian ratakan dengan kuas dan jangan sampai ada udara yang terjebak didalam serat fiber.

5) Untuk ketebalan yang diinginkan penambahan serat fiber dapat dilakukan pada saat penambalan yang pertama masih basah.

6) Setelah kering, lapisan tersebut digerinda untuk mendapatkan permukaan yang rata.

7) Selanjutnya dilakukan pendempulan untuk meratakan permukaan.

8) Pengecatan dapat dilakukan setelah lapisan dempul sudah bersih dan kering.

Adapun bahan-bahan FRP yang digunakan dalam perbaikan perahu fiberglass terdiri dari:

1) Minyak Resin (Epoxy Resin); bahan dasarnya terbuat dari minyak bumi dan residu tumbuhan. Adapun resin yang umum digunakan untuk konstruksi perahu adalah jenis orthophthalic polyester resin. Katalis (catalis) adalah cairan kimia untuk campuran minyak resin supaya terjadi pengerasan secara kimia atau sering juga di sebut hardener.

2) Talc; digunakan untuk membuat lem fiber (jackcoat) serta untuk membuat campuran cat plincoat.

3) Chopped Standard Mat (CSM) atau serat halus; terbuat dari bahan polyester sebagai media lapisan permukaan sebuah plat fiber.

4) Waven Roving (WR) atau serat kasar; terbuat dari bahan polyester/epoxy yang digunakan sebagai media lapisan tengah dari plat fiberglass. Serat penguat merupakan serat gelas yang memiliki kekakuan dan kekuatan tarik yang tinggi serta modulus elastisitas yang cukup tinggi.

5) Pigmen (pewarna); digunakan untuk memberi warna pada resin dan talc. 


\section{Metode Untuk Menangani Masalah}

Kegiatan pengabdian pada masyarakat ini dilaksanakan untuk memberikan solusi dari permasalahan mitra dalam perbaikan kerusakan perahu fiberglassnya. Metode pelaksanaan kegiatan ini dilakukan dengan memberikan teori dan praktek melalui ceramah dan diskusi kelompok secara terarah. Pelaksanaan teori diberikan sebanyak 35\% dan praktek sebanyak 65\%.

Kegiatan PPM ini dilaksanakan dengan tahapan:

1) Penyuluhan tentang teknologi bahan fiberglass, jenis-jenis kerusakan pada perahu fiberglass dan teknik perbaikannya. Materi ini disampaikan untuk membuka wawasan nelayan terhadap perkembangan teknologi kapal ikan fiberglass yang lebih maju dan ramah lingkungan. Selanjutnya dilakukan evaluasi pengetahuan peserta mengenai bahan fiberglass dan teknik perbaikan kerusakan perahu fiberglass.

2) Pelatihan perbaikan perahu fiberglass sesuai dengan metode perbaikan perahu fiberglass yang telah diberikan pada penyuluhan sebelumnya. Peserta pelatihan diminta mempraktekkan teknik perbaikan kerusakan pada perahu miliknya.

3) Evaluasi dilakukan untuk mengtahui tingkat pengetahuan peserta tentang bahan fiberglass dan teknik perbaikan perahu fiberglass yang dilakukan di akhir kegiatan penyuluhan dengan membandingkan hasil pre-test dan post-test. Evaluasi kemampuan dan keterampilan peserta dalam melakukan perbaikan perahu fiberglass dilakukan pada saat kegiatan pelatihan.

\section{Hasil dan Diskusi}

\subsection{Penyuluhan}

Transfer teknologi fiberglass pada kegiatan PPM ini dimulai dengan penyuluhan. Penyuluhan dimaksudkan untuk memberikan pengetahuan tentang teknologi kapal ikan berbahan fiberglass. Materi yang disampaikan dapat membuka wawasan nelayan terhadap perkembangan teknologi kapal ikan yang lebih maju dan ramah lingkungan. Peserta diberikan pengetahuan tentang pengenalan teknologi fiberglass (FRP), bahan-bahan dan metode pembuatan FRP, jenis-jenis kerusakan yang dapat terjadi pada perahu fiberglass dan bagaimana teknik perbaikan setiap jenis kerusakan tersebut. Kegiatan penyuluhan disampaikan melalui metode ceramah yang disertai dengan pemaparan video yang akan menambah wawasan dan pengetahuan mitra.

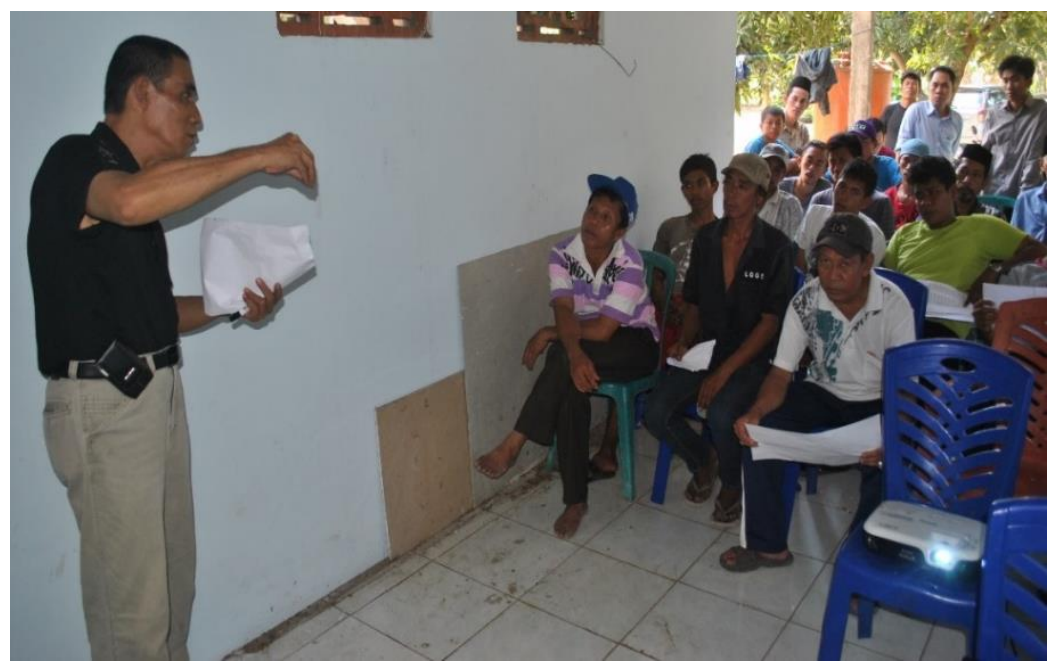

Gambar 1. Kegiatan penyuluhan Perahu Fiberglass 
Pada saat penyuluhan dibuka kesempatan diskusi untuk memenuhi kebutuhan informasi para nelayan mitra tentang teknologi yang diterapkan serta peluang kegiatan usaha perbaikan perahu fiberglass. Peserta pelatihan cukup antusias dalam mengajukan beberapa pertanyaan terkait teknologi fiberglass sebagaimana terlihat pada Gambar 1. Informasi yang diberikan dalam materi pelatihan mampu meningkatkan pengetahuan peserta yang terlihat dari perbandingan hasil pretest dan post-test diakhir kegiatan penyuluhan.

\subsection{Pelatihan}

Kegiatan alih teknologi selanjutnya adalah pelatihan reparasi kerusakan perahu fiberglass. Peserta diminta untuk mempraktekkan bagaimana memperbaiki kerusakan perahu fiberglass mereka sesuai dengan teknik perbaikan yang telah diberikan pada tahap penyuluhan sebelumnya. Kegiatan pelatihan ini diawali persiapan perahu yang akan diperbaiki. Peserta melakukan penandaan bagian perahu yang rusak, kemudian bahan fiberglass pada titik yang mengalami kerusakan dikupas hingga bersih. Peserta mempraktekkan cara membersihkan titik yang rusak hingga serat fiber yang lama kelihatan dan betul-betul dalam kondisi bersih dan kering.

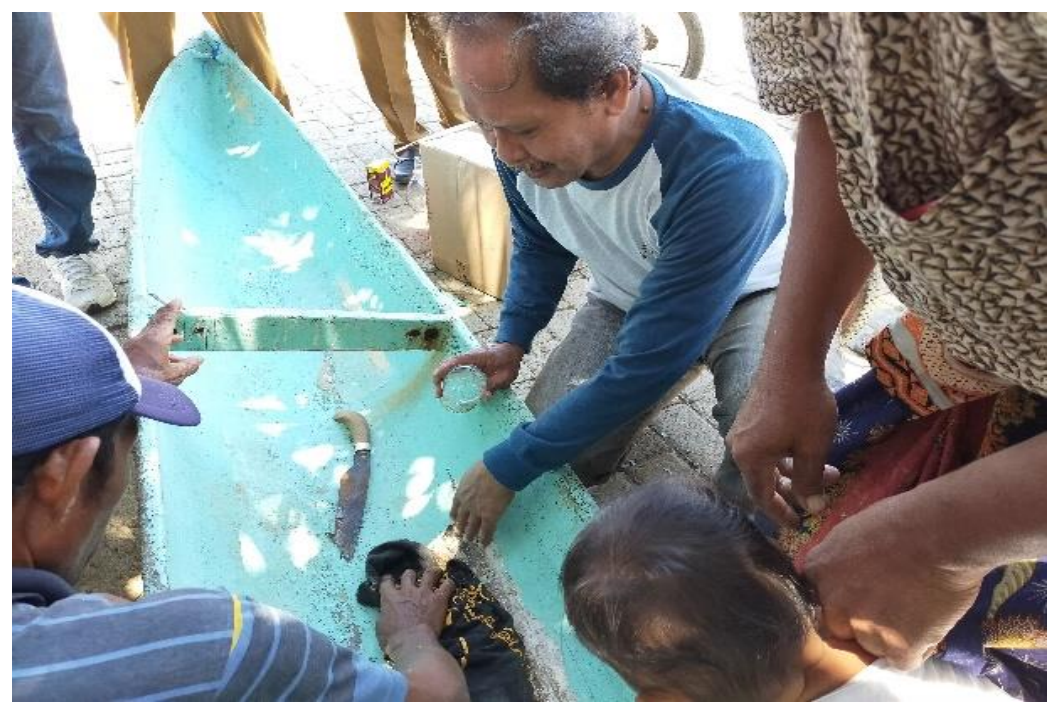

Gambar 2. Kegiatan persiapan perahu yang akan diperbaiki

Selanjutnya nelayan mitra melakukan praktek perbaikan terhadap kerusakan perahu fiberglass. Kegiatan praktek dimulai dengan meminta peserta untuk menyiapkan bahan-bahan dan peralatan kerja, kemudian mempraktekkan cara mencampur bahan fiberglass sesuai teori yang telah diberikan dan penggunaan alat bantu secara benar. Tim melakukan penilaian unjuk kerja peserta dalam mengenali jenis-jenis bahan dan kemampuan melakukan proses pencampuran bahan sesuai metode yang telah diberikan. Evaluasi unjuk kerja peserta menunjukkan bahwa peserta telah mampu mengenali jenis-jenis bahan dan mampu melakukan proses pencampuran bahan dengan benar sesuai metode yang telah diberikan. Selanjutnya peserta melakukan perbaikan sesuai dengan enis kerusakan yang terjadi. Peserta diminta untuk mendemonstrasikan cara perbaikan kerusakan sesuai dengan metode perbaikan yang telah diberikan sebagaimana terlihat pada Gambar 3.

Setelah perbaikan titik kerusakan selesai dilakukan, peserta merapikan area yang telah diperbaiki agar kondisinya kembali seperti semula dan perahu siap digunakan kembali. Selanjutnya peserta 
melakukan proses perbaikan perahu fiberglass mereka secara mandiri selama 2 (dua) minggu dan tim PPM akan melakukan evaluasi hasil kerja perbaikan tersebut.

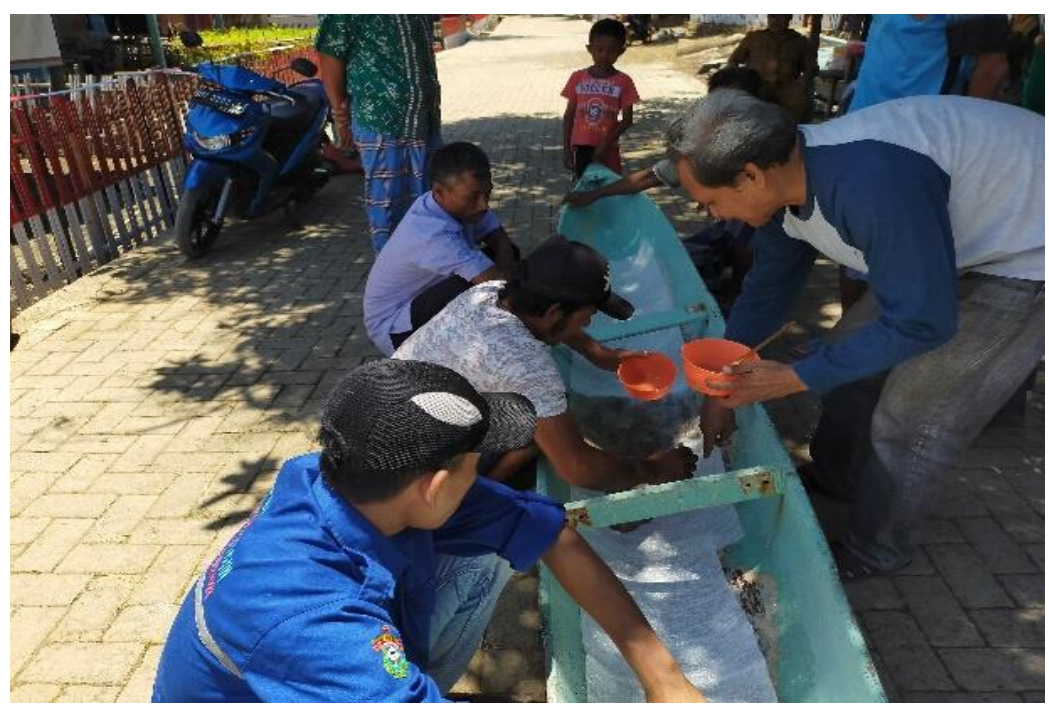

Gambar 3. Kegiatan praktek perbaikan Perahu Fiberglass

\subsection{Evaluasi}

Evaluasi kegiatan dilakukan untuk mengukur pencapaian hasil kegiatan PPM ini. Partisipasi peserta pada kegiatan ini termasuk baik yang ditunjukkan dengan kehadiran dan antusias peserta mengikuti kegiatan penyuluhan dan pelatihan. Hasil evaluasi berdasarkan hasil pre test yang dilakukan sebelum kegiatan penyuluhan menunjukkan pengetahuan peserta masih rendah terhadap bahan-bahan fiberglass; teknik mencampur bahan-bahan tersebut dan teknik perbaikan kerusakan perahu fiberglass. Hasil post test yang dilakukan setelah penyuluhan menunjukkan terjadi peningkatan pengetahuan dan keterampilan dimana semua peserta telah memiliki pengetahuan yang baik tentang bahan fiberglass dan teknik perbaikan kerusakan perahu fiberglass.
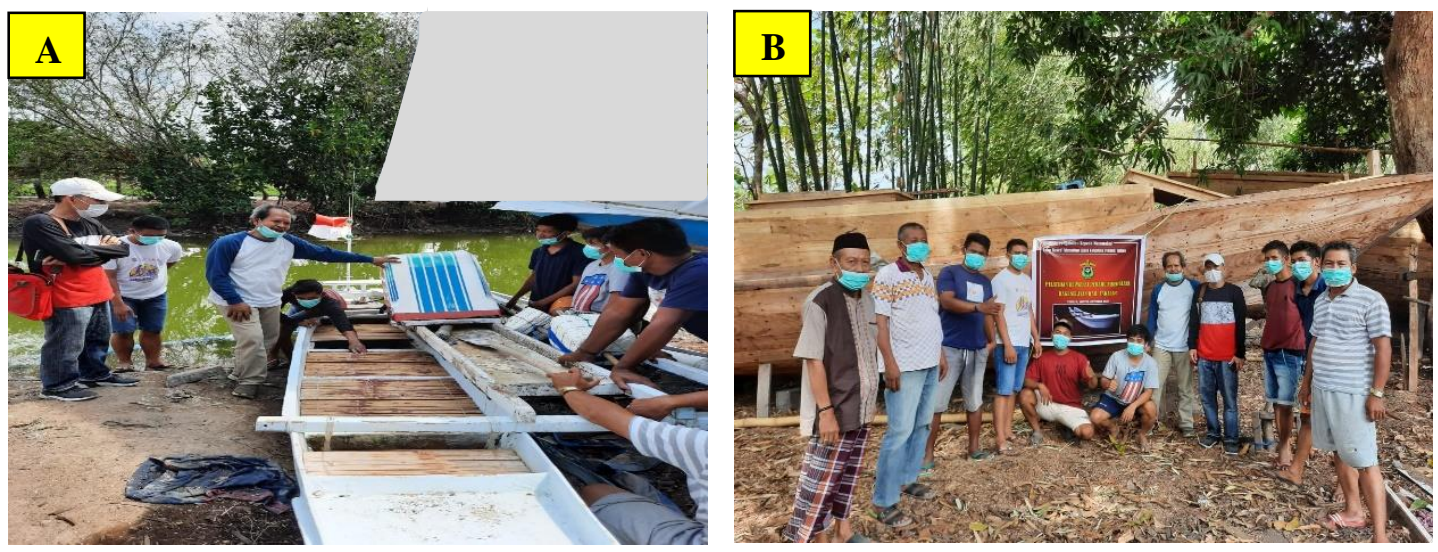

Gambar 4. A) Tim mengevaluasi hasil perbaikan kerusakan perahu peserta

B) Foto bersama tim dan peserta pelatihan perbaikan Perahu Fiberglass 
Pekerjaan perbaikan perahu fiberglass disamping membutuhkan pengetahuan yang baik tentang bahan fiberglass dan teknik perbaikan perahu, juga membutuhkan tambahan keterampilan menggunakan peralatan kerja sehingga akan diperoleh hasil perbaikan perahu yang lebih baik. Dari evaluasi unjuk kerja peserta selama pelatihan perbaikan perahu fiberglass menunjukkan $90 \%$ dari 10 orang peserta pelatihan telah mampu dan terampil memperbaiki kerusakan perahu fiberglass secara tepat dan benar.

\section{Kesimpulan}

Kegiatan PPM di Desa Galesong Kota ini berhasil mencapai target yang diharapkan bahwa semua peserta yang mengikuti penyuluhan telah memiliki pengetahuan yang baik tentang bahan fiberglass dan teknik perbaikan perahu fiberglass, dan $90 \%$ peserta pelatihan telah mampu melakukan perbaikan kerusakan perahu fiberglass secara tepat dan benar. Diharapkan mitra mampu menularkan pengetahuan dan keterampilan reparasi perahu fiberglass ini kepada nelayan lainnya yang berada disekitar lokasi mitra.

\section{Ucapan Terima Kasih}

Penulis mengucapkan terima kasih kepada Fakultas Teknik Universitas Hasanuddin, melalui pendanaan hibah LBE Pengabdian kepada Masyarakat Tahun Anggaran 2020. Ucapan terima kasih kepada ketua kelompok nelayan "Karya Bersama" atas kesediaannya sebagai mitra kegiatan pengabdian ini.

\section{Daftar Pustaka}

Badan Pusat Stratistik Kab.Takalar, (2018). Kecamatan Galesong Dalam Angka 2017. Badan Pusat Statistik Kabupaten Takalar.

Darmawan, (2018). Dokumen Rencana Pembangunan Jangka Menegah Desa Galesong Kota Kecamatan Galesong Kabupaten Takalar. Desa Galesong Kota, Takalar.

Bappeda Kab. Takalar, (2018). Profil Kabupaten Takalar, Terdapat pada laman http://takalarkab.go.id, Diakses pada tanggal 15 Januari 2019.

Wahyuddin, dkk. (2018). Pelatihan Perahu Kecil Fiberglass Reinforced Plastic (FRP) Untuk Budidaya Rumput Laut di Kabupaten Bantaeng. JURNAL TEPAT: Teknologi Terapan untuk Pengabdian Masyarakat, Vol. 1, No. 1(2018).87-98.

West System. (2014). Fiberglass Boat Repair \& Maintenance, Gougeon Brothers, Inc., BayCity, MI USA, pp. 002-550. 